author says, variations are recognizable only when the normal is known.

$\mathrm{He}$ is to be congratulated on his choice and the quantity of material collected for the illustrations. With hardly a single exception, each is a beautiful specimen of the condition under consideration. The quality of reproduction is excellent; it is doubtful if it could be better.

The fact that some of the very rare conditions have had to be omitted in no way detracts from the value of this contribution to dental radiographic literature. Any reader who has studied and learned all that is included will be certain to recognize the difference shown in the rare condition and be sure of its unusual character. Reference can then be made to one of the works devoted to such matters.

Our impression is that undergraduate, graduate and postgraduate will all derive great help and benefit from this work, then after courses of study are over it will remain a valued book of reference, for, though treatment, aetiology and even nomenclature may change, radiographic appearances will remain the same.

\section{A PRACTICAL MANUAL OF DISEASES OF THE CHEST}

By Maurice Davidson, M.A., M.D., F.R.C.P. 4th Edition. Pp. $x+647$, with 255 illustrations. London: Geoffrey Cumberlege. 1954. 84s.

This is the fourth edition of the book first published in 1935 , and like its forerunners it is very well planned and beautifully written and produced.

It is a formidable undertaking to write a comprehensive textbook on diseases of the chest, including pulmonary tuberculosis, and in view of the great recent advances the task of bringing such a book entirely up to date is almost as heavy.

Much work has been done by the author and his assistant in this respect, but in the section dealing with the treatment of pulmonary tuberculosis chemotherapy is hardly mentioned until the end, and therefore is not discussed as an integral part of other active therapy or as an increasingly used form of treatment on its own.

Some other points of criticism may be classed as controversial, but it is difficult to see the justification for the continued use of the old terminology of the anatomy of the bronchial tree, or for the recommendation of 10 per cent. cocaine as a local anaesthetic for bronchography, especially without strict instructions concerning the maximum dose and the steps to be taken to deal with the alarming complications that occasionally occur with the use of this drug.

In the treatment of tension pneumothorax the importance of the mechanical problem has not been adequately stressed. Surely a sharp pneumothorax needle should not be left in situ in the chest, whereas the value and safety of self-retaining, blunt-ended needles used in association with continuous underwater drainage, with or without suction, should have been mentioned.

The stressing of these practical points is necessary, but does not alter the fact that this is a comprehensive book of quality and character. It is most enjoyable to read, and chest specialists and general physicians will find in it a fund of information.

\section{CIBA FOUNDATION SYMPOSIUM}

\section{Hypertension: Humoral and Neurogenic Factors}

Edited by G. E. W. Wolstenholme, O.B.E., M.A., M.B., B.Ch., and Margaret P. CAMERon, M.A., A.B.L.S. Pp. xiv +294 , illustrated. London: J. \& A. Churchill, Ltd. I954. 30 s.

In this small volume are to be found the up-todate views of a great number of experts in the field of hypertension and its aetiology. It records the papers and discussions at a conference in July 1953 attended by more than 30 men of world-wide repute, from many countries, under the chairmano ship of Professor G. W. Pickering. In it one is privileged to be present at the often informal dison cussions between those who are the pioneers in this field. As a result there is a wealth of fascinating and absorbing matter in this book for those who wish to see where current research in the sphere of hypertension is leading.

The whole is so stimulating that it is perhaps wrong to treat it as the curate's egg. But the sections on phaeochromocytoma by Goldenberg and Peart, on the kidney in experimental hypertension by Floyer and on fluids and electrolytes by Ledingham were particularly notable. It is perhaps to be regretted that more distinction was not made by some speakers between hypertension and vascular disease, although even this error has its compensation in that the topic for discussion is thereby widened.

As a source of reference to modern research in cardiovascular physiology this book must be without rival. It will prove of great interest and value to all who wish to keep abreast of such subjects.

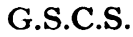

